\title{
Integrating Correctional and Community Health Care: An Innovative Approach for Clinical Learning in a Baccalaureate Nursing Program.
}

\author{
Mary T. Bouchaud \\ Thomas Jefferson University \\ Beth Ann Swan \\ Thomas Jefferson University
}

\section{Follow this and additional works at: https://jdc.jefferson.edu/nursfp \\ Part of the Public Health and Community Nursing Commons \\ Let us know how access to this document benefits you}

\section{Recommended Citation}

Bouchaud, Mary T. and Swan, Beth Ann, "Integrating Correctional and Community Health Care: An Innovative Approach for Clinical Learning in a Baccalaureate Nursing Program." (2016). College of Nursing Faculty Papers \& Presentations. Paper 76.

https://jdc.jefferson.edu/nursfp/76

This Article is brought to you for free and open access by the Jefferson Digital Commons. The Jefferson Digital Commons is a service of Thomas Jefferson University's Center for Teaching and Learning (CTL). The Commons is a showcase for Jefferson books and journals, peer-reviewed scholarly publications, unique historical collections from the University archives, and teaching tools. The Jefferson Digital Commons allows researchers and interested readers anywhere in the world to learn about and keep up to date with Jefferson scholarship. This article has been accepted for inclusion in College of Nursing Faculty Papers \& Presentations by an authorized administrator of the Jefferson Digital Commons. For more information, please contact: JeffersonDigitalCommons@jefferson.edu. 
Integrating Correctional and Community Health Care:

An Innovative Approach for Clinical Learning in a Baccalaureate Nursing Program

Mary T. Bouchaud, PhD, MSN, CNS, RN, CRRN

Jefferson College of Nursing, Thomas Jefferson University

Beth Ann Swan, PhD, CRNP, FAAN

Jefferson College of Nursing, Thomas Jefferson University 


\begin{abstract}
The system of health care in the United States is in crisis as it attempts to find more efficient and effective ways to improve the delivery of health care while ensuring quality and safety for those receiving that care. A culture change among nurse educators and administrators and in nursing education is needed to prepare competent practitioners capable of practicing from a health promotion, disease prevention, community and population focused construct in caring for a population of patients who are presenting health problems and conditions that persist across decades and/or lifetimes. Many baccalaureate nursing programs continue to prepare new RN's as generalists who function best in hospital-centric environments. In some cases, this is because programs with expanding student enrollment and competing nearby schools of nursing cannot find enough community organizations that can and will offer pre-licensure students precepted experiences. This paper describes how one institution uses prisons as an innovative clinical setting to educate nursing students about correctional and community/public health nursing and the new health care model of practice. It also describes the health care system within prison walls and how the use of prisons can prepare baccalaureate nursing students for nursing practice in the 21 st century.
\end{abstract}


Integrating Correctional and Community Health Care:

An Innovative Approach for Clinical Learning in a Baccalaureate Nursing Program

Health care in the United States has shifted from an acute care based model, to a

population health focused model. With this paradigm shift, the role of registered nurses (RNs) in non-acute care settings will continue to expand. Historically, the education of registered nurses (RNs) has emphasized hospital-based nursing because the majority of RNs work in hospitals. However, with the trend for more care to be delivered in outpatient and community settings, nursing education needs to effectively equip baccalaureate nursing students with the knowledge, skills, and competencies for expanding roles in ambulatory and community settings. Many national nursing organizations and reports have called for an educational curriculum that prepares professional registered nurses knowledgeable and skilled in population-based health competencies (American Association of Colleges of Nursing, 2008; Association for Prevention Teaching and Research, 2015; Institute of Medicine, 2011). The Institute of Medicine's (IOM) Future of Nursing: Leading Change, Advancing Health report called nursing schools to action in re-envisioning nursing education and nursing practice (IOM, 2011). A culture change among educators and leaders is needed to prepare competent professional registered nurses capable of practicing within a health promotion, disease prevention, community and population-focused construct (Bouchaud \& Gurenlian, 2013).

This call to action also includes a focus on new and emerging roles for nurses across the care continuum. With an evolving focus on primary, community-based, and patient-centered care rather than acute, hospital-centric care, and recognition of the importance of coordinating care and managing transitions across providers and settings of care, registered nurses need to be prepared with and from a different and broader knowledge base and skills set (Fortier, Fountain, 
Vargas et al., 2015). Basic competencies in epidemiology, biostatistics, environmental health, risk reduction and management, prevention of disease, disability, and injury, delivery of health care across the lifespan continuum and its application to chronic health care conditions, care of vulnerable populations, assessment of communities and populations, are essential for health care practice in today's current global-focused climate (Association for Prevention Teaching and Research, 2015).

While health care delivery is moving from the hospital to ambulatory and community settings, community-based educational opportunities are shrinking due to increasing regulatory requirements for student learners in a variety of community clinical sites. For example, for home care experiences, student must have their own car and singularly drive behind a home care nurse as he/she drives to every assigned patient's home for the entire day. Once in the home, the experience is often observational due to time constraints and productivity expectations. This has resulted in diminished learning experiences. There is missed dialog in route to the patient's home and post-visit due to driving in separate vehicles which impacts the student's ability to engage in clinical reasoning and analysis and evaluation of the community experience as it occurs in real time. This has resulted in a diminished learning experience and lost clinical opportunities for the students.

In response to these multiple national reports, and decreasing opportunities for hands-on community clinical experiences, a College of Nursing in the mid-atlantic region explored other possible organizations that had the capacity to support community clinical education. One organization that was explored was a correctional facility, a microcosm of society, offering baccalaureate nursing students learning opportunities in community and population-based care, cultural awareness, patient advocacy, ethics, professionalism, and strategies to implement health 
care utilizing a health promotion and disease prevention approach. Therefore, the purposes of this paper are to 1) discuss the use of maximum state and federal prisons as innovative educational settings for preparing baccalaureate nursing students for health care and nursing practice in the $21^{\text {st }}$ century; and 2) describe the health care system within the prison walls.

\section{Background}

Over the last 30 years, the number of incarcerated men and women has risen dramatically. The United States Department of Justice reports 6.8 million inmates in state and federal correctional facilities and local jails (Glaze \& Kaeble, 2014)). For most inmates, being arrested and imprisoned is their first real access to health care. The prison system is a large health care delivery system and in fiscal year 2011 , states spent a total of $\$ 7.7$ billion on correctional health care (Pew Charitable Trusts, 2014). The rising prison population has resulted in an aging inmate population with an increase in chronic illnesses, infectious diseases, and mental health and substance use disorders among inmates (Pew Charitable Trusts, 2014) as listed in Table 1. Overall, inmates are more likely to report ever having a chronic condition or infectious disease compared with the general population, and more women inmates report ever having a chronic condition compared to men (Maruschak, Berzofsky, \& Unangst, 2015). Over $57 \%$ of white inmates, over $51 \%$ of black/African American inmates, and over $40 \%$ of Hispanic/Latino inmates report ever having a chronic condition (Maruschak, Berzofsky, \& Unangst, 2015).

With this knowledge of correctional health care combined with limited availability of community clinical sites, and increased student enrollment, the author re-envisioned community placements and explored innovative clinical educational opportunities previously never 
considered that would enable students to embrace the changing model of health care delivery in the $21^{\text {st }}$ century.

\section{Getting Started}

Community health nursing is a topic explored in the final semester of the senior year. Students enroll in a didactic community health course with an associated community clinical education course. The description, objectives, and topics for both courses are listed in Table 2. In 2000, the author proposed a correctional health nursing clinical education experience in response to increasing enrollment and increasing competition for clinical sites in community/public health nursing. In addition, the author viewed this as a viable experience because the prison is a diverse community related to age, gender, race/ethnicity, socioeconomic background, and a variety of primary, secondary, and tertiary health care issues.

The author identified a 4,000 person, all male medium/maximum security state prison located in a rural community in southern New Jersey. In collaboration with the regional district prison nurse director, the state prison nurse manager, and the prison's director of nursing, the first correctional health community clinical education experience was developed and implemented with eight second degree accelerated pre-licensure baccalaureate nursing students who expressed interest in this new offering. Identifying a Point of Contact

Although the author had experience as a correctional nurse in a "sister" facility to the prison that was identified, there was difficulty accessing a point of contact to discuss a correctional health clinical education experience. The planning process took two years of numerous unanswered telephone calls and personal networking to ultimately obtain the home telephone number of the warden. The author's persistence and tenacity impressed the warden and the 
warden reluctantly agreed to consider the proposal, the first clinical education proposal the warden had ever received. Within five minutes of the call with the warden, the author was contacted by the regional director and a meeting was arranged for the author to tour the prison and present her proposal to the director of nursing (DON), the regional director, and the district manager. Subsequently, the proposal was presented to the head of the Department of Corrections (DOC). The author quickly learned that the prison nursing department reports to the division of medical services, the division is a "guest" of the DOC, and the faculty and nursing students are "guests" of the division of medical services. While prison nursing management was busy advocating for the nursing students' clinical education experience, the author needed to convince School of Nursing leadership and the University's legal department that the correctional health opportunity was a safe and viable clinical for students.

Establishing a Clinical Affiliation Agreement

Though the students would be mentored one-on-one at all times by a correctional health nurse with nursing school faculty rotating to each location within the compound to be with each student throughout the clinical day, and prison officers from the DOC would be in attendance at each medical site within the prison walls, concerns persisted. School leadership and the University's legal team worried about the safety of the nursing students during an eight-hour day in a medium/maximum security prison. They were concerned about the school's liability especially since there would be no way to reach the students or faculty while they were in the prison compound. Some administrators wondered whether any student would want to be placed in this rotation and if there would be family concerns.

The unexpected hurdle for the author was proving that correctional health was "really community nursing" and validating that the prison environment would provide a sound and 
quality community clinical education experience. The author mapped the community health nursing didactic course objectives and provided linkages with correctional health, and completed a similar exercise with the clinical course objectives. Once this innovative site was validated and there were systems in place to ensure student and faculty safety, the program earned approval, the clinical affiliation contract was finalized, and the correctional health clinical education experience launched in 2002. This correctional health community clinical opportunity immediately generated student interest, and became a staple in the clinical site offerings.

The inaugural group of eight students and one faculty were required to complete a criminal background check, child abuse check, Federal Bureau of Investigation (FBI) fingerprinting, six additional criminal clearance forms, and provide copies of the front and back of their driver licenses. The documents were sent to the prison and the review and approval process was completed in two months. In order for the faculty member to be allowed to move independently about the prison compound without an escort, she was required to complete additional clearances, as well as be re-fingerprinted on the first day at the prison. Orientation

Once all the student background checks are clear, the faculty meets with the students to brief them on prison rules, regulations, and protocols including: 1) entry regulations, 2) daily prison activities and rituals, 3) medical services and DOC interactions, 4) end of day exiting regulations, 5) interacting with security officers and prison inmates, 6) allowable student attire/clothing and how to present self, 7) items that can and cannot be brought into the lobby of the prison reception building, 8) items that can and cannot be brought into the actual prison cells and medical units, 9) activities that the students are permitted to do related to nursing practice and nursing care of celled inmates, and 10) safety. In addition, there is a discussion about the 
nurse/patient/inmate relationship. For health care interactions between a patient and a health care professional to work, it needs to be based on a trust versus trust relationship. That is, the health care professional trusts that the information the patient is giving is comprehensive, accurate, and truthful. The patient trusts that the health care professional will take that information and will be discriminate and non-judgmental in using and sharing that information to aid in getting the patient better (Minority Nurse Staff, 2013; Paris, 2006; Schoenly, 2011; Stevens, 1993).

In a correctional setting, the initial interaction between a health care professional and an inmate generally begins as a mistrust relationship. Unfortunately, often times that mistrust relationship continues in every interaction between the health care professional and the inmate. To begin, the inmate does not trust the health care professional. The inmate believes strongly that if the clinician was any good at all in what they are doing they would not be working in a prison. The inmate also believes it doesn't matter what they tell the health care provider regarding their symptoms or health concerns because the provider won't believe it anyway. There is an additional perception that no one really cares what happens to the inmates because they are criminals so they believe the care they will be receiving is subpar at best (Clayton, 2015; Minority Nurse Staff, 2013; Paris, 2006; Schoenly, 2011; Stevens, 1993).

Conversely, the health care provider does not initially trust the inmate because of the very setting they are practicing in; a prison, which houses criminals. Often times the provider believes criminals lie because they are malingerers who are seeking drugs, who are trying to get something over them, and who are just looking for a way "out of the joint." The perception is that the inmate broke the law which is why they are there so "why and how should I believe anything they are saying." These beliefs are generally perpetuated by the security officers who repeatedly enforce this mindset in their daily interactions with the inmates and medical personnel 
(Minority Nurse Staff, 2013; Stevens, 1993).

\section{Ensuring Student and Faculty Safety}

Students and faculty arriving at the prison are required to lock all personal belongings such as purses, wallets, book bags, etc. in the trunk or glove compartment of their car. They cannot bring any electronic devices into the prison reception building or the actual prison compound. All cell phones, iPads, and/or other electronic devices must be left at home or in their locked car in the parking lot. Students and faculty are not permitted to bring in any food or beverages except one unopened, sealed, no larger than 12-ounce bottle of water that must remain sealed until they are cleared and have entered the compound. They can wear and bring in coats, sweaters, gloves, scarves, and winter hats but no umbrellas. Scrubs or professional dress can be worn as long as no skin is showing. Clothes must be appropriately fitted to accommodate bending, stretching, and leaning over without resulting in low rise pants, exposing cleavage or abdomens, and/or without exposing chest hair or nipples. No tattoos or body piercings can be showing, no jewelry except for a watch, or plain ring band and no underwire bras as they set off the metal detector.

In the lobby of the prison reception building, there are lockers and for 50 cents the students or faculty can rent one locker to secure their car keys and any loose change or small items they did not want to keep in their car for the day. There is also a vending machine to purchase a bottle of water to take into the compound. Students and faculty can bring no more than three, one dollar bills to purchase soda and/or non-nutritive food from a vending machine in the dining halls when they go for lunch which is provided free of charge by the prison and prepared by the inmates. Though there is a regimented daily menu, for example every Monday is chicken, every Tuesday is pasta, there are also daily offerings of salad fixings, soups, vegetables, 
and sandwiches. In addition, homemade ice tea, milk, juice, coffee, hot tea, and fresh fruit are available along with a freshly baked sheet cake or other dessert. If a student is on medication or inhalers, the prison requires a prescription from their physician. The medication must be registered with the DON and with the head of the DOC on every visit.

Students must bring their driver's license or passport every day of clinical. The entry officer takes the students' drivers licenses and turns them over to the controlled entryway (sally port) officer who then exchanges them for visitor badges. The officer records each badge number in a log book with corresponding license name. The student is required to have that badge visible at all times throughout the clinical day and must return that same badge to the sally port officer at the end of the day to get their license or passport back. If the student forgets to bring a driver's license or a passport to clinical or is inappropriately dressed, the student cannot enter the prison compound and either has to go home or if he/she carpooled then must wait out the day in the prison reception hall. To further ensure student safety, students can only move about the prison compound if they are escorted by a prison badged staff member or the prison badged nursing faculty.

The nursing faculty has a permanent prison employee ID badge that is good for three years and must bring that on every clinical day. This badge must be visible at all times as it enables the faculty to move about freely and independently throughout the compound. If the faculty forgets the ID badge then he/she must submit their driver's license and follow the same procedure as the students including being unable to move throughout the compound without being escorted by a badged staff member.

Nursing students have been engrained to bring their own stethoscopes and manual sphygmomanometers, pathology textbook, and iPads to every clinical rotation. However, the 
prison only allows the students to enter the compound with one pen and a small notepad, preapproved and authorized medication, one tampon, three one dollar bills, and one 12-ounce sealed bottle of water. Their medical supplies and any published resources they may need are provided by the prison in each clinic locale throughout the compound. All nursing equipment and resources are counted at the beginning, randomly throughout, and at the end of each shift to insure that inmates do not have these items in their possession. Lastly, students cannot smoke during clinical and may not bring chewing gum, cigarettes, lighters or matches into the prison. In the last three years, the prison is a non-smoking facility and the inmates cannot smoke nor can any staff member smoke.

\section{Entering the Prison}

There are three shifts for the officers and medical personnel. The first shift starts at 6:00am and the reception building lobby gets bombarded with staff arriving and needing to get through security check points and sally ports to get to the time clock to punch in before their shift starts. Students arrive between 5:45am and 6:00am and must wait until all staff is cleared before lining up to go through the metal detector. Faculty needs to secure a locker and lock, insure students have not brought in any items that can be construed by the DOC as contraband. Once this process has been completed and faculty is confident that students are not bringing in any items other than what has been approved by prison regulations, the next step is to collect the drivers licenses and/or passports from each student and have them sign, date and time their entry into prison in a medical visitor log book. This way should something happen, the warden and DOC know exactly who is in the compound and where they are in the compound. Faculty turns over the licenses to the sally port officer and receives in equal exchange, prison visitor badges that are assigned to each student and then logged in a registry for safety and tracking purposes. 
Much like in an airport, students must remove their outer wear and place it, along with any items they are bringing into the prison, into a basin which is placed on a conveyor belt and sent through a scanner. While that is being cleared by security, the students and faculty must individually walk through the metal detector. If it rings the individual is given two more times to successfully pass through the body scan without setting off the alarm. Usually what sets off the alarm is underwire bras, failure to remove jewelry such as a watch or hidden chain, and shoes. However, it is at the discretion of the officer on duty to either wand and/or pat down the individual to secure clearance or simply refuse to allow the individual to enter the prison for that day.

A security officer is present in the exam room or cell or within close range to ensure safety of all nurses, medical personnel, students and faculty during all inmate interactions. If a situation appears to be suspicious or of any concern, and with all emergency scenarios, the officer will enter the scene first and no medical care can be provided until the DOC deems the situation to be cleared and safe. They take this responsibility very seriously and any visitor who violates the rules for any reason suffers the consequences which can range from being removed from the prison grounds and never permitted to return up to arrest and possibly jail time.

\section{Providing Health Care in a Correctional Health Community}

Students have the opportunity for quality hands-on community clinical opportunities including primary care through teaching, screening, and immunizations; secondary care through acute and episodic visits, triage in infirmary, and chronic care management; and tertiary care such as dialysis and minor surgery. One of the primary advantages of placing students in a prison facility is the medical/nursing experiences and opportunities that are available. There are three housing units in the prison compound and each of them offers an outpatient ambulatory 
general health clinic that is managed by a registered nurse $(\mathrm{RN})$. The office next to each general health clinic is a chronic care clinic run by a nurse practitioner (NP) or physician assistant (PA). Inmates who have a health care issue must first complete and submit to their assigned security officer, a "sick slip" to schedule an appointment to be seen by the RN in their general health clinic. All requests are honored within 24 hours. Inmates receive a written confirmation as to the time of their appointment and are informed that five dollars will be deducted from their personal account to pay for their health care visit. If the inmate requires further attention, then he is immediately seen by the NP and/or the in-house physician. All emergencies take priority over scheduled visits but all scheduled visits will be seen that same day. Inmates with chronic conditions are seen by the NP or PA on regularly scheduled appointments.

The prison also has an extended care unit (ECU) that houses older adult inmates much like a nursing home, chronically and terminally ill inmates, paraplegic and quadriplegic inmates requiring wound care, and there is a hospice and palliative care unit. The first few cells on the ECU are for inmates who are on suicide watch by the DOC with nursing oversight and require extensive monitoring round the clock and vigilant documentation. There is an infirmary that serves as a hospital acute care setting complete with isolation rooms, ventilators, IV and feeding pumps. Dental clinics, physical therapy, radiology department, telehealth for all neurology concerns, an infectious disease department, a 12 chair outpatient dialysis unit that runs six days a week, a locked behavioral unit with psychiatric-mental health nurses, group therapy sessions, and psychiatric counselors, and 24-hour medication administration and an in-house pharmacy rounds out the medical services afforded to all inmates.

On the first day of clinical, the nursing students are given an extensive orientation to the facility by the DON and the head of the DOC. They are escorted with the faculty around the 
entire compound, meet the nurse preceptors, and see the various health care facilities and opportunities. After their first lunch prepared by inmates, the students return to the conference room to discuss their clinical rotations. Each student can select where they want to begin their clinical rotation from the aforementioned sites. From then on the students rotate their clinical sites within the prison so that every student has the opportunity to experience all medical sites at least once during the rotation. In addition to the medical facilities, the prison offers diversity in health care issues, patient population, and nursing care concerns that enhance students' understanding of community and correctional health.

There are inmates who are homosexuals, in varying stages of transgendering, and from diverse socio-economic, educational, religious, and heritage backgrounds. Some are blind and/or deaf, paralyzed, in varying stages of cancer, and with acute and/or chronic conditions. For many, entering into the penal system is their first introduction to health care and learning they have medical concerns and health care issues. The possibility of inmate suicide requires a constant vigilance on the part of the medical and DOC staff, especially at the point of admission, immediately after court appearances, especially those where parole is denied, a new health care diagnosis especially related to cancer, loss of limbs, or impending or post-surgery. Depression is another health care concern for inmates that is either a result of being imprisoned or undiagnosed prior to incarceration. In addition, wound care, resulting from gun-shot injuries and paralysis, related to their crime and capture by the police, is extensive, costly, and numerous. Infectious and communicable diseases and dermatological challenges that arise due to the confinement of 4000 men and exposures to diversity that the average person would not normally be exposed to offer learning opportunities not seen in traditional health care environments. Lastly, communication with patients who do not speak or understand the English language, diversity in 
health literacy, institutional restrictions that challenge health care providers' ability to engage inmates in the management of their own health and health care issues, and having to work directly with cost containment issues, treatment and prevention product limitations and delays, and ethical dilemmas related to confinement and institutional protocols are invaluable clinical immersion experiences that cannot be taught in a classroom, simulation lab or in any other clinical site.

Students learn first-hand and early on the significance of universal precautions and how poor hygiene can quickly result in the spread of a contaminant that can result in an epidemic within the confines of the razor barbed wire community. Whatever any visitor has or brings with them into the prison walls can infect any employee and any inmate and has the potential to spread quickly and rampantly throughout the prison community. Conversely, as visitors exit the prison, they can bring anything they picked up from the other visitors and inmates back out to their families and communities and cause the same havoc outside the prison walls.

Because licensed practical nurses (LPNs) are responsible for medication administration, the nursing students do not get involved in this aspect of correctional health, except in the behavioral health unit. The students do however enter inmate cells accompanied by either a correctional nurse and/or their faculty to provide patient education, perform complete head to toe assessments including vital signs, wound care, and nursing care to all inmates in ECU and the infirmary. They work with the infectious disease nurse administering and reading purified protein derivative (PPD) skin tests, providing education related to infectious and communicable diseases especially for tuberculosis (TB) and Hepatitis $\mathrm{C}$ for inmates and the DOC, conducting all health screenings for incoming and outgoing inmates, and ensuring the integrity of all isolation rooms. Students are placed in all general health and chronic care clinics and are responsible for inmate 
visits and assisting with all first-aid and emergency care. In addition, the students assist inmates in morning glucose monitoring and insulin administration. They also work with a correctional nurse to handle all medical/nursing and DOC issues that occur with inmates in detention cells. The dialysis unit is run by an outside contracted company, therefore, students are only permitted to observe and ask questions of either the inmates and/or the dialysis nurses. In the behavioral unit, students are responsible for group sessions, afternoon medication administration, patient education, and any treatments or nursing care under the direct supervision of the nurses in that unit. They also get the opportunity to hear firsthand from the inmates, the effects of long term incarceration, impact undiagnosed and untreated or under treated illness and injury has on an individual, impact cultural health care beliefs have on health, and impact the limitations of institutionalization has on prevention strategies in promoting and sustaining health over time. Students rotate to the physical therapy department to appreciate the benefits of interprofessional collaboration in the maintenance of health for inmates.

\section{Evaluating the Correctional Health Community Experience}

At the end of the clinical day, all students are brought together with the faculty and the DON for a post conference and debriefing of the day's events. Students learn early on from their tour of the facility and their daily interactions with inmates that the prison is a microcosm of the outside community in which the inmates live complete with community housing and resident issues, environmental issues, work programs, diversity in culture, language and religious practices, and limited health care resources. In addition, students get a real lived experience regarding the effect limited to no resources and social determinants has on prisoner patients and why they appear to be "non-compliant" and "frequent flyers." This leads to a better understanding on the part of the students regarding the economic toll this has on the health care 
delivery system. Since 85 to 95 percent of all inmates return to the community, students recognize how essential it is to educate inmates about their health and well-being and how to prevent disease and disability and ideally these lessons will be carried over to the students' next clinical rotation and ultimately their professional $\mathrm{RN}$ practice. In addition, each student is required to identify a nursing practice, health care issue or concern, or ethical dilemma in the prison that is different from what they have seen and learned thus far in their nursing program. Once approved by faculty, students research their topics using an established course rubric and then present it to faculty, their peers, and the DON at post conference. The intent is for students to demonstrate the relationship and significance of community-based principles of care and population based nursing practice in promoting health and preventing disease and in particular its impact on the delivery of cost effective and quality patient care. Additionally, their presentation and clinical experience in the prison should identify to the students how their nursing contributions may reduce or prevent recidivism in correctional health, as well as be transferable to patients they will see in acute care and ambulatory settings.

The initial group of eight students who pioneered this innovative community health setting in a medium/maximum correctional facility has grown in the last 13 years. Over 400 baccalaureate nursing students have completed community clinical education experiences in prisons resulting in the prison hosting students five days a week for a period of three weeks. The community clinical expectations also changed over the years from a split rotation where students completed half of their scheduled time in a home care site and the other in a public health setting or prison to students completing their entire community clinical hours at one specific site be it home care, a public health site, or prison. This change promoted a longer exposure to community principles, specific populations, and new community/nursing roles for the $21^{\text {st }}$ 
century. This change, coupled with the promotion of the prison experience by senior students to junior students, generated interest that led to the need to partner with another 4000 person all male maximum security state prison located in another state, as well as a 3000 person male/female federal prison. In addition, student sign up for these three prisons has become so popular that there are over 45 requests and a waiting list for all three prisons. Currently, the author is collaborating with the MSN nurse practitioner (NP) program and the first NP student began a correctional health clinical experience in the federal prison in September 2015.

Another change in the clinical program that occurred in the last decade is rather than faculty providing both didactic and clinical teaching, adjunct faculty are now hired to teach in the clinical setting. This change had a substantial impact on the prison rotation because the initial prison had been comfortable with having the author for eight or nine years. The challenge was to find an MSN prepared RN with an interest in correctional health and teaching experience. The program successfully recruited seasoned nurses with no correctional health experience but with interest in correctional health but unfortunately each individual only lasted a semester and did not want to go back. One new clinical faculty left midway through the semester and the author had to replace her so the students could complete their rotation. In recent years, the program has been fortunate in finding clinical faculty for two of the state prisons who not only want to return to the prison but who were asked to return by the prison officials. The author remains the faculty for the federal prison and has recently recruited a faculty for the NP students. Student Perspectives

Since its inception in 2002, the correctional health community experience has been evaluated favorably. When asked "What did you expect prior to entering the prison?" students responded that they did not have any expectations. Some reported that they heard the rotation 
provided interesting clinical cases and numerous learning experiences. One student stated, "I was really scared at first but still wanted to go." Another student stated, "I was somewhat apprehensive but excited, a little intimidated by the idea of inmates but I kept an open mind." When asked their opinion of the prison itself, as well as what they now thought of correctional health, students responded extremely positive: "I learned numerous concepts regarding wound care, medications, assessments, psychology, etc.," "I believe this rotation has been the best experience of nursing school and I am not sure they will be able to trump this rotation," and "this has been a really amazing rotation. I have learned and seen things that I could not have anywhere else and got a glimpse into another world."

The responses to questions pertaining to feeling safe while in the prison, on the dialysis unit, or when directly interacting with inmates in units or their cells was a resounding, "yes, I always felt safe," "safe $100 \%$ of the time," "yes, the professionalism and caution of medical personnel and presence of the officers made me feel very safe," and "yes, I never felt in harm's way at the prison." All the students recommended the prison as a community clinical site: "yes, completely unique and an amazing experience," "I would recommend this rotation to everyone if they had the opportunity," "the observations and skills performed during this rotation are remarkable and unlike any other rotation available in nursing school," "community within a community with its own special care considerations, it's an amazing experience," "the overall experience is very unique in terms of community, psychosocial and health needs," "I think a rotation here teaches how to react without the availability of unlimited supplies while in a contained environment," and finally, "this is a "must do' rotation." All students stated that they were treated professionally. 
The students rated the various health care units throughout the prison rotation good to excellent. Comments included: "great wound care experience," "great triage experience," "good PPD experience and life learning," "very well organized," "great hands on experience," "very caring, respectful, nonjudgmental, kind nursing staff," "I had many clinical experiences I had not had previously," "learned a lot regarding the spread of disease and infection control," and “excellent patient-centered care."

Students who have completed their community rotation in correctional health in medium-maximum security prisons continue to share their experiences with other students including those currently enrolled as well as those considering enrolling in the university. Their word of mouth praises have raised the interest level to a degree that has and continues to require the need for more contracted prison sites, an increased need for additional faculty, and an extensive student request list. This author has now extended her prison opportunities in three states, and to juvenile detention centers, federal prisons, and additional state correctional facilities. Her future goals include the development of a correctional health curriculum and a qualitative research study.

\section{Summary}

This article proposed an alternative and innovative solution to the dilemma of limited and decreasing available community clinical sites to prepare baccalaureate nursing students for health care practice in the $21^{\text {st }}$ century. It demonstrated how medium/maximum prisons can provide an ideal learning experience for not only technical nursing skills but more importantly for reinforcing key learning goals for community-based care, raising population based awareness, and promoting cultural awareness. A discussion was presented on how to begin a clinical partnership with prison facilities, how to ensure student and faculty safety, and included 
a suggestion for post clinical assignments to solidify clinical course and nursing program objectives. This article addressed the challenges and solutions to overcome those challenges when initiating and maintaining clinical placement in a correctional facility. Finally, this article presented the changes in clinical policies in one college of nursing's program and how the innovative use of private, state, and federal prisons could be a model for other university nursing programs. 


\section{References}

American Association of Colleges of Nursing. (2008). The essentials of baccalaureate education for professional nursing practice. Washington D.C.: American Association of Colleges of Nursing.

Bouchaud, M. \& Gurenlian, J. (2013). A qualitative study on preparing baccalaureate nursing students for community/public health nursing as perceived by nurse educators and administrators. International Journal of Nursing, 2(2), 1-13.

Clayton, E. (2015). Correctional Nurses-Time to Overcome the Stigma of Correctional Nursing. Retrieved from www.nursingald.com/articles/12942-correctional-nursing.

Fortier, M., Fountain, D., Vargas, M., Heelan-Fancher, L., Perron, T., Hinic, K., \& Swan, B.A. (2015). Health care in the community: Developing academic/practice partnerships for care coordination and managing transitions. Nursing Economic\$, 33(3), 167-175, 181.

Glaze, L. \& Kaeble, D. (2014). Correctional populations in the Unites States, 2013. Washington D.C.: U.S. Department of Justice.

Healthy People Curriculum Task Force. (2015). Clinical prevention and population health curriculum framework. Washington D.C.: Association for Prevention Teaching and Research.

Institute of Medicine. (2011). The future of nursing: Leading change, advancing health. Washington D.C.: The National Academies Press.

Maruschak, M., Berzofsky, M., \& Unangst, J. (2015). Medical problems of state and federal prisoners and jail inmates, 2011-12. Washington D.C.: U.S. Department of Justice.

Minority Nurse Staff. (March, 2013). Correctional facility nursing. Retrieved from minoritynurse.com/correctional-facility-nursing/. 
Paris, J.E. (2006). Interaction between correctional staff and health care providers in the delivery of medical care. In M.Puisis (Ed.). Clinical practice in correctional medicine ( $\left.2^{\text {nd }} \mathrm{Ed}\right)$. Philadelphia: Mosby Elsevier.

Schoenly, L. (2011). Are correctional nurses outcasts? Correctional Nurse.Net. Retrieved from correctionalnurse.net/.

Stevens, R. (1993). When your clients are in jail. Nursing Forum, 28(4), pp. 5-8.

The Pew Charitable Trust \& John D. \& Catherine T. MacArthur Foundation. (2014). State prison health care spending: An examination. Philadelphia: The Pew Charitable Trusts.

Wilper, A., Woolhandler, S., Boyd, J., Lasser, K., McCormick, D., Bor, D., \& Himmelstein, D. (2009). The health and health care of US prisoners: Results of a nationwide survey. American Journal of Public Health, 99(4), pp. 666-672. 
Table 1. Health Problems Reported by Prison and Jail Inmates

\begin{tabular}{|l|c|c|}
\hline \multicolumn{1}{|c|}{ Chronic Diseases: } & Prison Inmates & Jail Inmates \\
\hline Arthritis & & $12.9 \%$ \\
\hline Asthma & $15 \%$ & $20.1 \%$ \\
\hline Cancer & $14.9 \%$ & $3.6 \%$ \\
\hline Diabetes & $3.5 \%$ & $7.2 \%$ \\
\hline $\begin{array}{l}\text { Heart Disease and Heart } \\
\text { Related }\end{array}$ & $9 \%$ & $10.4 \%$ \\
\hline High Blood Pressure & $9.8 \%$ & $26 \%$ \\
\hline Stroke and Stroke-Related & $30 \%$ & $2.3 \%$ \\
\hline Overweight and Obesity & $1.8 \%$ & $62 \%$ \\
\hline \multicolumn{1}{|c|}{ Infectious Diseases: } & $74 \%$ & $14 \%$ \\
\hline Hepatitis B & $21 \%$ & $1.7 \%$ \\
\hline Hepatitis C & $2.7 \%$ & $5.6 \%$ \\
\hline HIV/AIDS & $9.8 \%$ & $2.5 \%$ \\
\hline Sexually Transmitted Diseases & $6 \% \%$ HIV positive & $1 \%$ \\
\hline Tuberculosis & $6 \%$ & \\
\hline & & \\
\hline $\begin{array}{l}\text { Prescription Medication for } \\
\text { Current Chronic Condition }\end{array}$ & & \\
\hline
\end{tabular}

Information adapted from the U.S. Department of Justice, Office of Justice Programs, Bureau of Justice Statistics http://www.bjs.gov/content/pub/html/mpp/mpp.cfm 
Table 2. Community Health Nursing Courses

\begin{tabular}{|c|c|c|}
\hline & $\begin{array}{l}\text { NU410: } \\
\text { Community Health Nursing }\end{array}$ & $\begin{array}{c}\text { NU411: } \\
\text { Clinical Practicum VI }\end{array}$ \\
\hline $\begin{array}{l}\text { Course } \\
\text { Description }\end{array}$ & $\begin{array}{l}\text { This course prepares the student for the } \\
\text { promotion of health in communities through } \\
\text { primary, secondary, and tertiary prevention. } \\
\text { Uses nursing and public health principles to } \\
\text { promote and preserve the health of populations. }\end{array}$ & $\begin{array}{l}\text { This course provides students with Community } \\
\text { Health Nursing clinical practice experiences that } \\
\text { are directed toward wellness and health } \\
\text { alterations with a primary focus on health } \\
\text { promotion and maintenance. Emphasis is on } \\
\text { individuals, families and community groups } \\
\text { from culturally diverse populations. Selected } \\
\text { clinical settings will provide opportunities for } \\
\text { students to provide primary, secondary, and } \\
\text { tertiary nursing care through collaboration with } \\
\text { individuals, families, community, community } \\
\text { leaders, and health professionals. }\end{array}$ \\
\hline $\begin{array}{l}\text { Course } \\
\text { Objectives }\end{array}$ & $\begin{array}{l}\text { Differentiate between population focus and } \\
\text { individual focus care. } \\
\text { Validate patient care priorities based on } \\
\text { individual and community need. } \\
\text { Critique the impact of illness on the coping } \\
\text { and adaptive patterns of individuals and } \\
\text { communities. } \\
\text { Identify the role of the community health } \\
\text { nurse in a variety of community settings. } \\
\text { Identify the importance of community } \\
\text { members in the planning and implementation } \\
\text { of a community intervention. } \\
\text { Explain the health status of communities using } \\
\text { epidemiological concepts, biostatistical data } \\
\text { and research. } \\
\text { Analyze current community health issues } \\
\text { affecting the health and care of specific } \\
\text { populations. } \\
\text { Identify environmental health hazards in the } \\
\text { community. }\end{array}$ & $\begin{array}{l}\text { Analyze theoretical and empirical knowledge } \\
\text { from nursing, the humanities and the physical, } \\
\text { environmental and behavioral sciences in } \\
\text { providing nursing care for the individual, family } \\
\text { and community. } \\
\text { Utilize the nursing process in providing } \\
\text { primary, secondary, and tertiary } \\
\text { prevention for individuals, families, and } \\
\text { communities from culturally diverse } \\
\text { populations. } \\
\text { Analyze clinical nursing problems using } \\
\text { data gathered from current nursing and } \\
\text { related research data. } \\
\text { Demonstrate effective communication } \\
\text { with individuals, families, and } \\
\text { communities. } \\
\text { Perform multiple complex skills in an } \\
\text { organized manner with a consistent } \\
\text { degree of accuracy. } \\
\text { Assume accountability for } \\
\text { interdependent nursing actions in } \\
\text { providing nursing care in the community } \\
\text { setting. } \\
\text { Utilize nursing interventions to initiate } \\
\text { change in health behaviors of the } \\
\text { individual, family and community. } \\
\text { Demonstrate leadership skills in } \\
\text { collaborating with individuals, families, } \\
\text { communities and other professionals. }\end{array}$ \\
\hline
\end{tabular}




\begin{tabular}{|c|c|c|}
\hline & & $\begin{array}{l}\text { Utilize the nursing process in program planning } \\
\text { and evaluation. }\end{array}$ \\
\hline $\begin{array}{l}\text { Course } \\
\text { Topics }\end{array}$ & $\begin{array}{l}\text { History, Principles, and Practices of Public } \\
\text { Health and Community Health Nursing. } \\
\text { Introduction to Biostatistics and Epidemiology } \\
\text { Community Concepts } \\
\text { Concepts of Community Health and Aggregate } \\
\text { Health } \\
\text { Overview of Community Health Settings } \\
\text { Introduction to Environmental } \\
\text { Health/Environmental Hazards } \\
\text { Vulnerable Populations } \\
\text { Disaster Management and Disaster } \\
\text { Preparedness } \\
\text { Local, National, and Global Health } \\
\text { Economics of Health Care in the Community }\end{array}$ & $\begin{array}{l}\text { Community Health Nursing Concepts and } \\
\text { Overview } \\
\text { Physiological Adaptation } \\
\text { Reduction of Risk Potential } \\
\text { Safe, Effective Treatment and Procedures }\end{array}$ \\
\hline
\end{tabular}

